\title{
Subacute coronary stent thrombosis in a patient developing clopidogrel associated thrombotic thrombocytopenic purpura
}

\author{
M-A von Mach, A Eich, L S Weilemann, T Münzel
}

Heart 2005;91:e14 (http://www.heartjnl.com/cgi/content/full/91/2/el4). doi: 10.1136/hrt.2004.049122

\begin{abstract}
Clopidogrel, in combination with aspirin, is commonly used for the prevention of thrombosis in patients who have received coronary artery stents. As a rare but critical complication, clopidogrel associated thrombotic thrombocytopenic purpura (TTP) has previously been described. A 78 year old man presented with unstable angina and filiform subtotal stenosis of the left anterior descending artery. $\mathrm{He}$ was treated with balloon angioplasty and stent implantation. After four days the patient again had angina caused by stent thrombosis, which was treated with balloon angioplasty. During hospital stay the typical course of clopidogrel associated TTP was observed with thrombocytopenia and petechial purpura occurring 14 days after drug initiation and prompt response to therapeutic plasma exchanges. These findings strongly suggest that clopidogrel may have increased platelet activation and aggregation in this immunologically susceptible patient, ultimately leading to a stent thrombosis.
\end{abstract}

\section{A} 78 year old man was referred to our department with unstable angina. Coronary angiography showed a subtotal stenosis of the proximal left anterior descending artery, which was treated with balloon angioplasty and stent implantation (fig 1A). For prevention of stent thrombosis the patient received a loading dose of $500 \mathrm{mg}$ aspirin intravenously and $300 \mathrm{mg}$ clopidogrel orally followed by a daily oral dose of $100 \mathrm{mg}$ aspirin and $75 \mathrm{mg}$ clopidogrel. Additionally, the patient continuously received unfractionated heparin through an infusion pump with a targeted activated partial thromboplastin time of 50 seconds. Despite a good result following the primary coronary intervention (fig 1B) and the antithrombotic medication the patient again experienced chest pain four days later. The coronary angiogram showed a complete occlusion of the previously implanted stent in the left anterior descending artery (fig lC), which was treated with balloon angioplasty (fig 1D). Screening for thrombophilia showed a heterozygous prothrombin G20210A mutation. After 14 days the patient's platelet count dropped rapidly to a minimum of $4 \times 10^{9} / 1$. Treatment with aspirin and clopidogrel was stopped and lepirudin was administered instead of heparin for anticoagulation. Serological testing for heparin induced thrombocytopenia type II was negative. Thereafter, the patient developed petechial purpura of the trunk and thighs (fig 2) and did not respond to platelet transfusions.

Clopidogrel associated thrombotic thrombocytopenic purpura (TTP) was suspected and therapeutic plasma exchange was initiated on day 19 after admission. After the first plasma exchange the platelet count increased from $4 \times 10^{9} / 1$ to $44 \times 10^{9} / 1$ and, after the second exchange, to $66 \times 10^{9} /$.
Metalloproteinase (ADAMTS13) activity was found to be reduced to $26 \%$ (normal range 58-134\%) and large von Willebrand factor (vWF) multimers were present. After a total of six therapeutic plasma exchanges every other day the platelet count was normal at $200 \times 10^{9} / 1$ to $400 \times 10^{9} / 1$ (two months' follow up).

\section{DISCUSSION}

We report on a patient with subacute stent thrombosis during treatment with clopidogrel who subsequently developed clopidogrel associated TTP. The critical question that needs to be addressed is whether the substance that was administered to prevent thrombus formation in the implant actually increased the risk for platelet activation and aggregation in the patient concerned.

Idiopathic TTP occurs at an annual rate of about four per million and is a life threatening multisystemic disease with a mortality rate of $10-20 \% .{ }^{1}$ Various substances have been found to be associated with TTP and in the context of angioplasty and stent implantation ticlopidine and clopidogrel have acquired particular clinical importance. ${ }^{23}$ Owing to a more favourable safety profile, clopidogrel has achieved widespread clinical acceptance. ${ }^{4}$ It is commonly used for the prevention of thrombosis in patients who have received coronary artery stents. The standard regimen consists of a loading dose of $300 \mathrm{mg}$ followed by $75 \mathrm{mg}$ daily. ${ }^{5}$ The subacute thrombosis observed in the present patient led to screening for thrombophilia, which detected a heterozygous prothrombin G20210A mutation. The 20210A allele is associated with higher prothrombin concentrations in heterozygotes than in non-carriers and with an almost threefold increased risk of venous thrombosis. ${ }^{6}$ However, the present patient had an arterial thrombosis and was given continuous heparin. It therefore seems unlikely that the prothrombin mutation played a major part in the occurrence of stent thrombosis. The rapid drop in platelet count within the first two weeks of clopidogrel treatment (in 65\% of the previously reported patients ${ }^{3}$ ) accompanied by petechial purpura and the prompt response to therapeutic plasma exchange resembled the typical course of clopidogrel associated TTP. The total number of plasma exchanges corresponded well with previous studies, which determined a median of eight plasma exchanges required to achieve remission. ${ }^{1}$

In view of the coincidence of stent thrombosis preceding the clopidogrel associated TTP that we observed, the molecular mechanisms of TTP need to be determined. Recently, the metalloproteinase ADAMTS13 has been identified as vWF cleaving protease. ${ }^{7}$ In idiopathic TTP, reduced ADAMTS13 activity, or autoantibodies inhibiting its activity, result in the formation of large vWF multimers, which are important in the pathogenesis of thrombotic thrombocytopenia. Patients with ticlopidine associated TTP were found to 

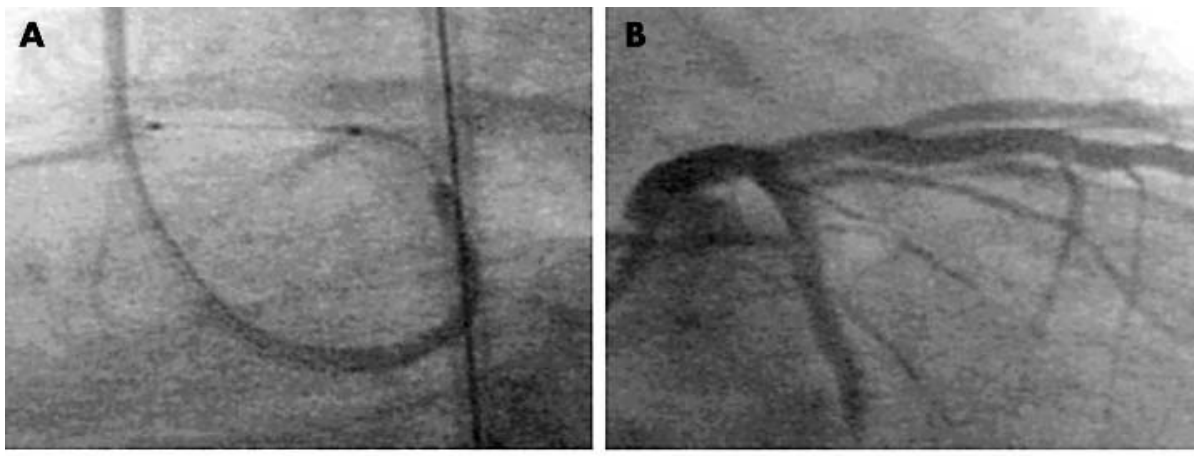

Figure 1 (A) Stent implantation on the day of admission into the left anterior descending artery with (B) a good result. (C) Thrombotic stent occlusion after four days (arrow) and (D) the reopened coronary artery after balloon angioplasty.
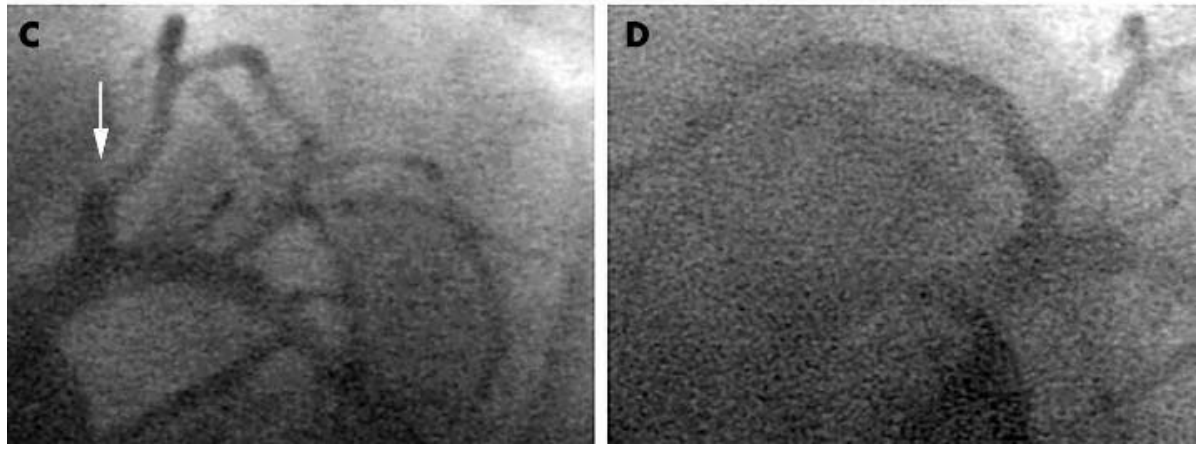

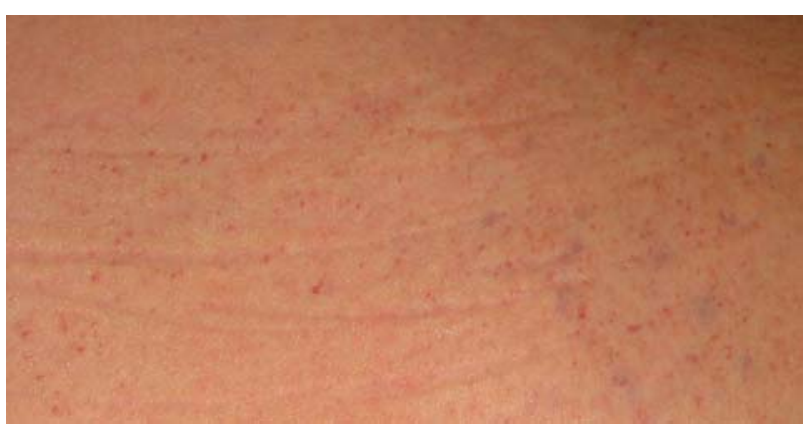

Figure 2 Petechial purpura of the trunk accompanying severe thrombocytopenia.

be severely deficient in vWF metalloproteinase and large vWF multimers could not be detected, indicating different underlying mechanisms in this context. ${ }^{8}$ For clopidogrel associated TTP data are rare and both normal and reduced ADAMTS13 activity has been observed. This also points to a different mechanism from that with ticlopidine (both are derivatives of thienopyridine) probably because of their minor structural differences and different metabolites. ${ }^{9}$ A prospective study of 300 patients to investigate the role of the metalloproteinase in clopidogrel associated TTP is in progress. $^{3}$ In the present patient we found a reduced ADAMTS13 activity associated with large vWF multimers during the active period of TTP. Presumably these abnormalities, which may be the result of pathological immune responses, were preceded by the binding of clopidogrel to the platelet surface leading to an increased risk of platelet activation and aggregation even before the clinical manifestation of TTP.

\section{Authors' affiliations}

M-A von Mach, A Eich, L S Weilemann, T Münzel, II Medical

Department, University Hospitals, Mainz, Germany

Competing interest statement: The authors are not aware of any grant, business interest, or consultancy that could lead to a conflict of interest.

Correspondence to: Dr M-A von Mach, II Medical Department, University Hospitals, Langenbeckstrasse 1, 55131 Mainz, Germany; marcm@giffinfo.uni-mainz.de

Accepted 6 September 2004

\section{REFERENCES}

1 Bennett CL, Connors JM, Carwile JM, et al. Thrombotic thrombocytopenic purpura associated with clopidogrel. N Engl J Med 2000;342:1773-7.

2 Steinhubl SR, Tan WA, Foody JM, et al. Incidence and clinical course of thrombotic thrombocytopenic purpura due to ticlopidine following coronary stenting. EPISTENT Investigators. Evaluation of platelet llb/llla inhibitor for stenting. JAMA 1999;281:806-10.

3 Zakarija A, Bandarenko N, Pandey DK, et al. Clopidogrel-associated TTP. Stroke 2004;35:533-8.

4 Bertrand ME, Rupprecht HJ, Urban P, et al. Double-blind study of the safety of clopidogrel with and without a loading dose in combination with aspirin compared with ticlopidine in combination with aspirin after coronary stenting: the clopidogrel aspirin stent international cooperative study (CLASSICS) Circulation 2000; 102:624-9.

5 Müller I, Seyfarth M, Rüdiger S, et al. Effect of a high loading dose of clopidogrel on platelet function in patients undergoing coronary stent placement. Heart 2001;85:92-3.

6 Ceelie H, Spaargaren-van Riel CC, Bertina RM, et al. G20210A is a functional mutation in the prothrombin gene: effect on protein levels and $3^{\prime}$-end formation. J Thromb Haemost 2004;2:119-27.

7 Fujikawa K, Suzuki H, McMullen B, et al. Purification of human von Willebrand factor-cleaving protease and its identification as a new member of the metalloproteinase family. Blood 2001;98:1662-6.

8 Tsai HM, Rice L, Sarode R, et al. Antibody inhibitors to von Willebrand factor metalloproteinase and increased binding of von Willebrand factor to platelets in ticlopidine-associated thrombotic thrombocytopenic purpura. Ann Intern Med 2000;132:794-9.

9 Sharis PJ, Cannon CP, Loscalzo J. The antiplatelet effects of ticlopidine and clopidogrel. Ann Intern Med 1998;129:394-405. 